\title{
Ventricular tachycardia with retrograde conduction
}

Sir,

In his Letter to the Editor (British Heart Fournal (1976), 38, 771) Dr. Marriott criticises the paper of Evans and associates (1974) on 'Ventricular tachycardia with retrograde conduction' and blames the paper's shortcomings on what he calls the authors' 'P-preoccupation syndrome'. Though I agree that the identification of $P$ waves does not by itself prove or disprove the ventricular origin of a tachycardia, it seems to me that the urge to learn as much as possible about the atrial rhythm in an electrocardiogram of tachycardia does not deserve a nosological designation. In many cases this knowledge forms the basis for further information as it did for instance in a case seen by me in 1963.

A 54-year-old man was admitted with a paroxysm of tachycardia. The conventional electrocardiogram showed abnormal ventricular complexes shaped like those seen in left bundle-branch block, with a slightly irregular rate around 200 a minute. In leads II, III, and aVF the tops of most ventricular complexes were notched but the notches were missing in some solitary complexes. An oesophageal lead which was recorded simultaneously with lead II identified the notches as $P$ waves. The PR relation revealed retrograde conduction to the atria with Wenckebach-type block of varying degree. Pressure on the eyeballs did not affect the rhythm of the ventricles but suppressed the retrograde conduction (with disappearance of the notches in lead II) and established atrioventricular dissociation. At this juncture atrial tachycardia was excluded but it was recognised that the differentiation between a junctional and a ventricular tachycardia was not achieved.

Slow intravenous injection of a 10 per cent procainamide solution was started and the oesophageal electrocardiogram was recorded every minute (Fig.); both the atrial and the ventricular rate decreased slowly. During a particular intermediate phase of the injection-when $0.6 \mathrm{~g}$ procainamide were injected-the relative timing of the $P$ and $R$ waves allowed every fifth sinus impulse to capture the ventricles and to produce a ventricular complex which later, when sinus rhythm was restored, proved to be identical with that of sinus beats. Careful inspection of the tracing taken after the injection of $0.4 \mathrm{~g}$ procainamide showed a solitary fusion beat; its nature was suggested by the intermediate shape of the ventricular complex and was confirmed by the timing of the preceding $P$ wave. Neither before the injection nor in its final phases were the conditions favourable to the appearance of capture or fusion beats and none was found. Only the monitoring of the oesophageal tracings during procainamide injection led to the detection of the transient period in which fusion and capture beats could be expected and occurred. The therapeutic procedure yielded the marginal benefit of a diagnostically useful sign (Puech et al., 1970), which brought the diagnosis one step nearer to certainty.

I am aware of the objections to overestimation of ventricular captures and of fusion beats as supposed final proof of the ventricular origin in tachycardias. Objections can be raised equally to an overreliance upon QRS morphology as the final criterion of differential diagnosis; both approaches involve statistical probability and call for every bit of additional evidence. The unearthing of $P$ waves has a special attraction for the routine-bound clinician: in our science fiction dreams we of the pre-His-electrogram generation were fascinated by the cardiac impulses as they emerged, propagated, entered, re-entered to and fro, and collided all over the myocardium. In the waking hours all that reached our senses from this animated world were the two signals of the atrial and the ventricular deflection in our tracing. From this meagre material deductive thinking had to reconstruct mechanisms of abnormal cardiac rhythm much as a palaeontologist reconstructs the shape of an extinct animal on the evidence of single bones. Every additional bone is precious. Therefore, the electrocardiographer who indulges in $\mathrm{P}$ detection should not feel neurotically guilty even when the immediate practical application of his findings is not guaranteed. 'One never knows what findings of importance may be uncovered in the course of a quest after the truth.' (Marriott and Myerburg, 1974.)

\section{Peter Fleischmann, ${ }^{1}$ 40 Wedgwood Avenue, Haifa, Israel.}

${ }^{1}$ Formerly of Central Emek Hospital of the General Labour Sick Fund, Afula, Israel. 

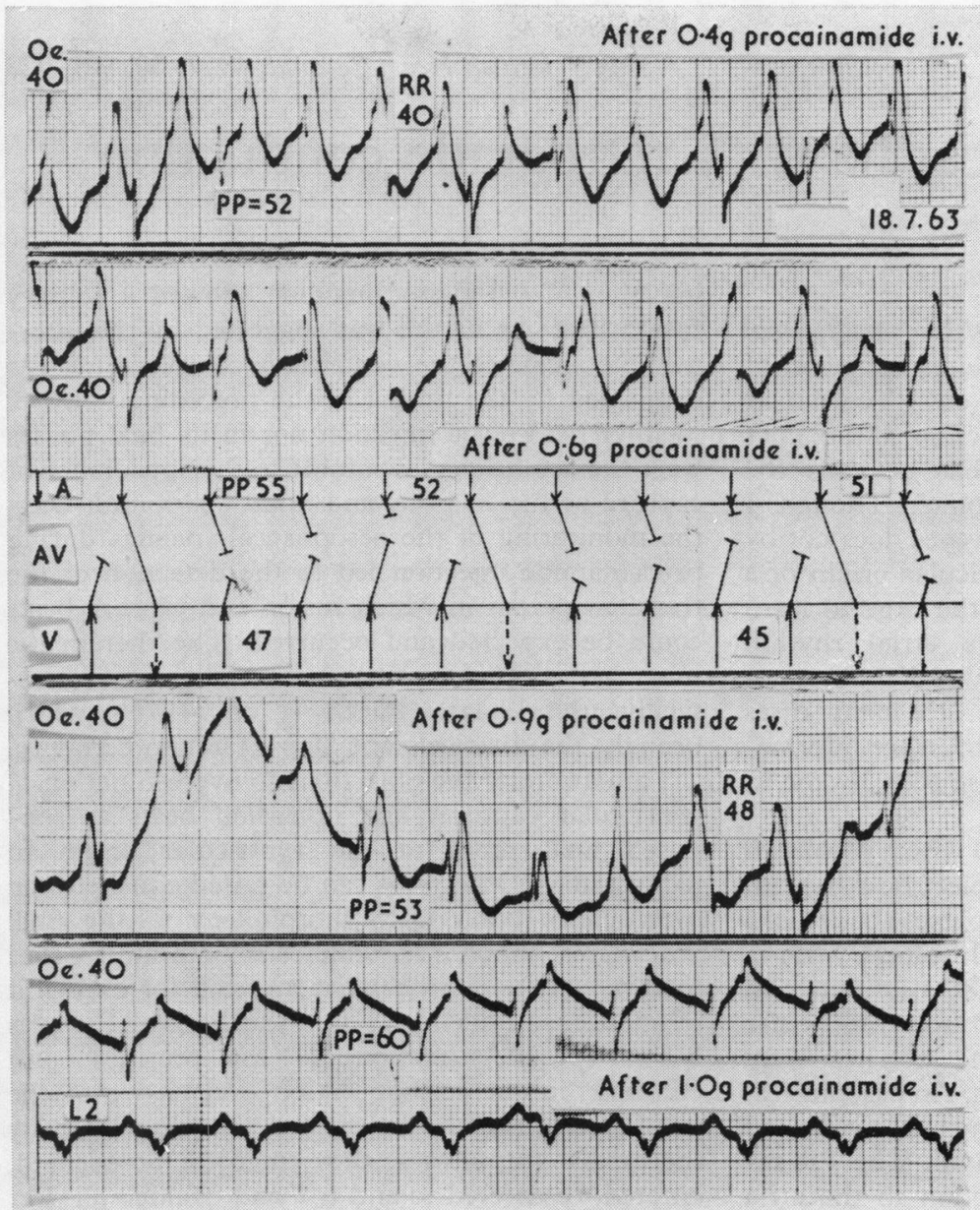

Fig. Atrioventricular dissociation in 'almost certain' ventricular tachycardia. Panels 1-3: Strips of oesophageal lead (40 cm from the nares), taken at the end of intravenous injection of $0.4,0.6$, and $0.9 \mathrm{~g}$ procainamide. Top panel, centre: one fusion beat. 2nd panel : three capture beats (diagram). Bottom panel: simultaneous record of the oesophageal lead and lead II taken after the injection of $1.0 \mathrm{~g}$ procainamide and the restoration of sinus rhythm.

\section{References}

Evans, G. L., Charles, M. A., and Thorrsvard, C. T. (1974). Ventricular tachycardia with retrograde conduction. Simplified diagnostic approach. British Heart fournal, 36, 512-515.

Marriott, H. J. L., and Myerburg, R. J. (1974). Recognition and treatment of cardiac arrhythmias and conduction disturbances. In The Heart, 3rd ed., p. 536. Chief Editor: J. W. Hurst. McGraw-Hill, New York.

Puech, P., Grolleau, R., Fijac, E., and Posner, J. (1970). The diagnosis of supraventricular arrhythmias and the differentiation between supraventricular tachycardias with aberrant conduction and ventricular tachycardias. In Symposium on Cardiac Arrhythmias, p. 211. Ed. by E. Sandøe, E. Flensted-Jensen, and K. H. Olesen. AB Astra, Södertälje, Sweden. 